\title{
Extracellular Vesicles as Emerging Players in Intercellular Communication: Relevance in Mast Cell-Mediated Pathophysiology
}

\author{
Irit Shefler ${ }^{1,2, *(\mathbb{D}}$, Pazit Salamon ${ }^{1}$ and Yoseph A. Mekori ${ }^{1,2,3}$ \\ 1 The Herbert Mast Cell Disorders Center, Laboratory of Allergy and Clinical Immunology, Meir Medical \\ Center, Kfar Saba 4428164, Israel; pazit.salamon@clalit.org.il (P.S.); ymekori@gmail.com (Y.A.M.) \\ 2 Sackler School of Medicine, Tel Aviv University, Tel Aviv 6997801, Israel \\ 3 Tel Hai College, Tel Hai 1220800, Israel \\ * Correspondence: irit.shefler@clalit.org.il; Tel.: +972-97472198
}

Citation: Shefler, I.; Salamon, P.; Mekori, Y.A. Extracellular Vesicles as Emerging Players in Intercellular Communication: Relevance in Mast Cell-Mediated Pathophysiology. Int. J Mol. Sci. 2021, 22, 9176. https:// doi.org/10.3390/ijms22179176

Academic Editor: Giovanna Traina

Received: 22 July 2021

Accepted: 23 August 2021

Published: 25 August 2021

Publisher's Note: MDPI stays neutral with regard to jurisdictional claims in published maps and institutional affiliations.

Copyright: (c) 2021 by the authors. Licensee MDPI, Basel, Switzerland. This article is an open access article distributed under the terms and conditions of the Creative Commons Attribution (CC BY) license (https:// creativecommons.org/licenses/by/ $4.0 /)$.

\begin{abstract}
Mast cells are major effector cells in eliciting allergic responses. They also play a significant role in establishing innate and adaptive immune responses, as well as in modulating tumor growth. Mast cells can be activated upon engagement of the high-affinity receptor FceRI with specific IgE to multivalent antigens or in response to several FceRI-independent mechanisms. Upon stimulation, mast cells secrete various preformed and newly synthesized mediators. Emerging evidence indicates their ability to be a rich source of secreted extracellular vesicles (EVs), including exosomes and microvesicles, which convey biological functions. Mast cell-derived EVs can interact with and affect other cells located nearby or at distant sites and modulate inflammation, allergic response, and tumor progression. Mast cells are also affected by EVs derived from other cells in the immune system or in the tumor microenvironment, which may activate mast cells to release different mediators. In this review, we summarize the latest data regarding the ability of mast cells to release or respond to EVs and their role in allergic responses, inflammation, and tumor progression. Understanding the release, composition, and uptake of EVs by cells located near to or at sites distant from mast cells in a variety of clinical conditions, such as allergic inflammation, mastocytosis, and lung cancer will contribute to developing novel therapeutic approaches.
\end{abstract}

Keywords: mast cell; extracellular vesicles; inflammation; cancer

\section{Introduction}

Mast cells (MCs) are derived from hematopoietic progenitor cells that enter almost all vascularized tissues, where they complete their maturation. [1-3]. MCs are known as essential effector cells in eliciting allergic responses and play a key role in innate and adaptive immunity. They are associated with a wide variety of pathophysiological processes, including tissue damage repair, thrombosis and homeostasis, autoimmune injury, and mastocytosis [2,4-6]. MCs are also often found at the site of tumors and are a component of the tumor microenvironment (TME). They function to promote or restrict tumor growth, depending on the mediators they release $[5,7,8]$.

MCs are well-recognized by two kinds of highly expressed cell surface receptors: FceRI, which is the IgE receptor, and c-kit (CD117), which is the stem cell factor (SCF) receptor. MCs can be activated by the binding of allergen-specific IgE via cross-linking of the FceRI. MCs may also be activated via several FceRI-independent mechanisms as well, including microbial products that signal through Toll-like receptors (TLR), direct injury, compounds known as basic secretagogues, IgG-antigen complexes, peptides, complement, proteases, and several cytokines and chemokines [9-13]. In addition to soluble mediators, we have shown that MCs can be activated by direct interaction with activated T cells or their microvesicles [14]. 
Upon activation, MCs can release a variety of bioactive mediators that are pre-stored in cytoplasmic granules (a process known as degranulation), including histamine, heparin, proteases, proteoglycans, and antimicrobial peptides. They can also selectively produce and release newly synthesized potent inflammatory mediators such as leukotriene C4 (LTC4), prostaglandin D2 (PGD2), and several pro- and anti-inflammatory cytokines and chemokines $[9,10,15,16]$. In addition to releasing different mediators, MCs secrete extracellular vehicles (EVs) spontaneously or in response to different stimuli [17].

EVs are membrane-surrounded structures that are secreted by various cell types. They are detectable in many biological fluids, including blood, urine, saliva, breast milk, amniotic fluid, ascites, cerebrospinal fluid, bile, and semen, as well as in conditioned media of cell cultures [18-21]. Once released to the extracellular space, EVs circulate in body fluids and modulate the metabolism of both neighboring and distant cells via the horizontal transfer of bioactive molecules, including proteins, lipids, DNA, RNA, and microRNA to recipient cells [22,23]. They have been implicated in several physiological and pathological processes, such as immune disorders, inflammation, neurological diseases, and cancer [19,24-26].

EVs are heterogeneous structures that differ from each other based on their biogenesis and size. They can be divided into three main subgroups: microvesicles, exosomes, and apoptotic bodies. Microvesicles range in size from 150 to $1000 \mathrm{~nm}$ and are formed by the outward budding and fusion of the plasma membrane.

Exosomes refer to smaller vesicles ranging from 30 to $150 \mathrm{~nm}$ in size. They are derived from the endosomal-lysosomal pathway by inward budding into endosomes, as intraluminal vesicles (ILV) within large multivesicular bodies (MVB), and then released to the extracellular space by fusion of MVB with the plasma membrane. Apoptotic bodies are heterogeneous vesicles. They vary from 50 to $5,000 \mathrm{~nm}$ in diameter and are released from cells undergoing apoptotic cell clearance [19,24,27].

Both EV subsets (microvesicles and exosomes) overlap in size and express some common identifying markers; making it more difficult to classify them. Therefore, guidelines published by the International Society for Extracellular Vesicles currently recommend using the term "EVs" when there is uncertainty about the subcellular origin of the vesicles [28]. In the present review, we chose to use the term "EVs" instead of the exact vesicle subset that was documented in the original articles.

Several lines of evidence suggest that EVs released by MCs may convey biological function by delivering them to distant target cells, thereby affecting inflammation, allergic response, and tumor progression. Furthermore, MCs can also be affected by EVs derived from other cells in the immune system or in the TME, which may lead to activating MCs to release different mediators [29]. In the present review, we discuss findings published in the last decade, using EVs and MCs as keywords. We focused on EVs derived from MCs and their potential roles in inflammation, allergic response, and cancer procreation, as well as the ability of EVs secreted from other cells to influence MCs in these conditions.

\section{Mast Cells as the Origin of Extracellular Vesicles}

\subsection{Relevance of Mast Cell-Derived Extracellular Vesicles in Allergic Response and Inflammation}

Data are continually emerging on the ability of MCs to exert interactions with other cells located in their proximity by secreting numerous mediators from their pre-stored granules and by releasing EVs $[29,30]$. MCs are able to release EVs either constitutively or upon stimulation. The composition of MC-derived EVs may differ in size, protein, lipid, and RNA and DNA content based on MC activation status and the type of MC stimuli. Thus, they have distinct functions [30-32].

Several reports have shown that MCs secrete EVs during FceRI-induced degranulation [31]. Kormelink et al. showed that both mucosal-type MCs and connective tissue-type $\mathrm{MCs}$, which represent the two main functionally different murine MC phenotypes, constitutively release EVs under resting conditions and have remarkably high amounts of EVs upon FceRI cross-linking [17]. EVs derived from activated MCs were enriched with 
the EV marker CD63 and differed in their buoyant density, size, and lipid composition, as compared to EVs derived from resting MCs. Additionally, these activated MC-EVs contained high amounts of functional MC-specific mediators that were previously described as soluble only, as compared to EVs derived from resting MCs. Furthermore, activated MC-EVs release was found to correlate with $\beta$-hexosaminidase release [17]. Comparisons of the expression patterns of proteins, long non-coding RNAs, and miRNAs in EVs isolated from resting or FceRI-activated bone marrow-derived mast cells (BMMCs) revealed that stimulated-EVs contained higher levels of tryptase, MC carboxypeptidase A, and IL-4 in contrast to resting-EVs [33]. The basic genomic features of the identified long non-coding RNAs and the length of the miRNAs differed between these two EV types, suggesting a potential regulatory function of MC-derived EVs [33]. However, the role of MC-derived EVs in the context of allergic reactions is still controversial. For example, EVs isolated from FceRI-activated MCs displayed IgE and antigens on their surface, which enabled their efficient internalization by IgE-loaded MCs, mainly by endocytosis through the binding of antigens on EVs and IgE bound to MCs [34]. This internalization resulted in $\beta$-hexosaminidase release, a marker of MC degranulation, and induction of cytokine production at a level similar to that obtained by FceRI cross-linking. These findings indicate a self-amplification mechanism that can contribute to exacerbation of local allergic reactions. FceRI-mediated EVs uptake may also deliver antigens to other immune cells, such as FceRI-positive dendritic cells (DC), further contributing to allergic responses [34]. Allergic diseases are characterized by increased serum levels of total $\operatorname{IgE}$ and specific $\operatorname{IgE}$ against common allergens, thereby activating the FceRI on MCs. The sera of atopic individuals displayed varying amounts of EV-associated IgE that positively correlated with serum IgE levels, whereas IgE levels could not be detected on EVs purified from the sera of nonatopic donors. Moreover, only EVs derived from atopic individuals carried the FceRI- $\alpha$ chain, supporting the assumption that these EVs display FceRI/IgE complexes [34].

On the other hand, it has recently been shown that MC-derived EVs may have a protective role in allergic asthma. EVs derived from unstimulated BMMCs harbored FceRI and could bind and neutralize free $\mathrm{IgE}$ in the serum, thus inhibiting MC activation by reducing its levels. In addition, in a mouse model of allergic asthma induced by exposure to ovalbumin, intravenous injection of MC-derived EVs eased the airway hyperresponsiveness over time. This improvement was accompanied by a remarkable decrease in ovalbuminspecific IgE in serum and histamine levels in bronchoalveolar lavage fluid. Changes in bronchoalveolar lavage fluid cytokine levels were also noticed. Furthermore, MC-derived EVs significantly modulated airway remodeling in allergic asthma, a suppressive effect that was positively correlated with treatment duration [35].

Communication between MCs and group 2 innate lymphoid cells (ILC2) in allergic inflammation occurs in the lungs, small intestine, and skin lesions of patients with atopic dermatitis. It has recently been demonstrated that interactions between MCs and ILC2 occurs via EVs. IgE-activated synovium-derived cultured MCs released EVs that can interact and be internalized into ILC2. The interaction of these EVs with ILC2 cells that were pre-activated with IL-33 led to enhanced production of type 2 cytokines such as IL-5 but not IL-13. Ekström et al. [36] and Valadi et al. [37] reported that MC-derived EVs contain miRNAs, which can be transferred to other cells and continue to function in these recipient cells. Indeed, the effect of MC-EVs on ILC2 could be attributed to miR103a-3p, which is highly expressed in EVs derived from activated MCs. The transfer of miR103a-3p to ILC2 via EVs resulted in the downregulation of protein arginine methyltransferase 5 expression, which led to enhanced IL-5 production. Furthermore, EVs from the sera of patients with atopic dermatitis express significantly higher levels of miR103a-3p than do EVs from the sera of nonatopic donors. Thus, miRs in EVs derived from human MCs following FceRI aggregation might enhance the inflammation seen in atopic dermatitis [38].

Neuroinflammation is a response of the central nervous system to external stimuli, including surgery, infection, and toxins. It is manifested in part by the microglial activation and release of proinflammatory cytokines. Several studies have reported the central and 
peripheral MC critical roles in neuroinflammation by interacting with microglial cells to increase their migration and release of proinflammatory cytokines. An example of this interaction was found to occur via EVs released from LPS-activated MCs, which could transfer miR-409-3p to microglia, causing the downregulation of nuclear receptor subfamily 4 group A member (2Nr4a2) expression and activation of the NF- $\mathrm{kB}$ pathway, thereby promoting microglial migration, activation, and neuroinflammation [39].

In addition to miRs, EVs also contain and transfer extracellular RNA, such as ribosomal RNA, to recipient cells. Recently, it was established that EVs containing ribosomal RNA are released from MCs during exocytosis and degranulation. Thereafter, these EVs induced the release of pro-inflammatory cytokines such as MCP-1 and IL-6, as well as procoagulant responses in human umbilical cord vein endothelial cells in an extracellular RNA-dependent manner [40].

MCs can indirectly initiate the antigen-dependent $\mathrm{T}$ cell response by releasing EVs containing MHC class II and co-stimulatory molecules. Indeed, these MC-derived EVs had the capacity to induce B and T lymphocyte proliferation and cytokine production, which correlated with the induction of a Th1-type immune response, involving the production of IL-2, IL-12, and IFN- $\gamma$, but not IL-4 $[29,41]$. EVs derived from BMMCs enhanced the differentiation of naive $\mathrm{CD} 4^{+} \mathrm{T}$ cells to Th2 cells. This effect was found to occur, at least partially, by direct surface contact via ligation of OX40L present on MC-EVs with OX40 present on the surface of $\mathrm{T}$ cells, rather than by endocytosis [42].

Morphologic studies have documented an increase in the local density and activation of MCs in T cell-mediated inflammatory processes, as observed in psoriasis [43]. Indeed, a recent study has provided evidence that EVs derived from MCs are the source of cytosolic phospholipase $\mathrm{A} 2$ contributing to a CD1a-reactive $\mathrm{T}$ cell response in psoriasis patients [44].

Altogether, these findings provide evidence of the ability of MC-derived EVs to deliver certain messages and to act as mediators that contribute to immunomodulatory and/or immunoregulatory properties by interacting with other cells in distant sites.

\subsection{Relevance of Mast Cell-Derived Extracellular Vesicles in Tumor Progression}

Tumor progression is determined not only by the tumor cells themselves but also by their interactions with their surroundings, known as the TME. The TME has a dynamic composition that includes various cell types, such as immune cells, blood and lymphatic vessels, cancer-associated fibroblasts, tumor-associated macrophages, and myeloid-derived suppressor cells $[45,46]$. In the TME, the tumor cells communicate with each other and with stromal and immune cells via a sophisticated intercellular communication system through direct cell-to-cell contact or by classical paracrine signaling loops of cytokines or growth factors. MCs are often found in the microenvironment of several human solid and hematologic tumors and function as a component of the TME [7]. Accumulating data suggest that MCs have diverse roles in tumor biology. They were found to play both proand anti-tumorigenic roles in the TME depending on the tumor type and its developmental stage [5,7]. They can be pro-tumorigenic by affecting various events of tumor progression such as angiogenesis, proliferation invasiveness, survival, and metastasis. This can be mediated by releasing mediators such as histamine, prostaglandins, tryptase, $\beta$-FGF, TGF$\beta, V E G F$, and IL-8. In contrast, the anti-tumorigenic effects of MCs include direct growth inhibition, immunologic stimulation, and decreased cell mobility. These effects involve the release of chymase, tryptase, TNF- $\alpha$, and IL-9 [5,7,47-49].

Emerging data demonstrate that EVs are important in the mechanism of the cellular interchange of bioactive molecules. A number of studies have suggested that tumor cells communicate with each other and with neighboring microenvironmental cells via EVs, which coordinate various steps of tumor progression such as proliferation, angiogenesis, metastasis, and drug resistance [50]. Increasing evidence suggests that EVs derived from MCs have distinct functions in tumor progression. For example, EVs derived from HMC-1, a human neoplastic MC cell line, contain the KIT receptor, but not c-KIT mRNA. These EVs can be internalized into the A549 lung cancer cell line, which leads to enhanced 
proliferation and migration of the lung cancer cells by activating the PI3K/AKT signaling pathway [51]. Furthermore, EVs derived from MCs were also found to induce the epithelial to mesenchymal transition in these cells due to the induction of protein phosphorylation cascades known to be involved in this transition phenotype [52].

Several studies have explored the role of EVs derived from neoplastic MCs on systemic mastocytosis (SM). SM is a clonal disorder that harbors abnormal MC proliferation and pathological accumulation in several tissues, including bone marrow, lymph nodes, skin, liver, and spleen. SM displays various degrees of severity, from indolent to more aggressive forms. Among patients with SM, somatic mutations in c-kit that encodes for the KIT receptor have been detected in the bone marrow, as well as in skin and peripheral blood cells. The most common somatic mutation, Asp816Val (D816V), is located in the catalytic domain of KIT and results in augmented MC proliferation and survival [53]. The sera of SM patients contain high concentrations of small EVs that express hallmarks of MCs, such as FceRI, MRGPRX2, tryptase, and activated KIT receptors. In addition, the concentration of these EVs correlated with other SM disease parameters such as serum tryptase. In liver biopsies obtained from SM patients, MCs infiltrate around hepatic portal areas, which is associated with development of liver fibrosis and other hepatic abnormalities [54]. Indeed, EVs derived from the sera of SM patients or from the human HMC-1 cell line affected the activation of hepatic stellate cells (HSC) by transferring active KIT from SM-EVs into the HSC cell line, resulting in proliferation, cytokine production, and differentiation of $\mathrm{HSC}$, a process associated with liver pathology. The authors also demonstrated that injection of SM-EVs, but not EVs from healthy control subjects, into recipient mice resulted in increased $\alpha$-SMA expression, a marker of HSC activation, around portal areas. These findings suggest a role for KIT within SM-EVs in the activation of HSC in vivo [55].

SM patients have high rates of osteoporosis and other bone diseases in association with the presence of MCs infiltrating bone marrow [56]. EVs derived from SM patients or from the HMC-1 MC cell line delivered miR-23a and miR-30a into pre-osteoblast cells. The internalization of these miRs via SM-EVs prevented osteogenic transcriptional programs, thus controlling their differentiation into osteoblasts, inhibiting bone production, and contributing to bone diseases, both in vitro and in vivo [57].

\section{Mast Cells as Targets of Extracellular Vesicles}

\subsection{The Contribution of Extracellular Vesicles to Mast Cell-Induced Non-Allergic Responses}

In addition to the function of EVs released by activated MCs, accumulated data published by our group and others have documented that EVs originating from various cell types can activate MCs [29].

The close physical proximity observed between MCs and T lymphocytes in inflamed tissues has raised the possibility of a functional interaction between these two cell populations. Indeed, morphologic studies have documented an increase in the local density of MCs and their activation during $\mathrm{T}$ cell-mediated inflammatory processes, as observed in cutaneous delayed-type hypersensitivity, sarcoidosis, inflammatory bowel disease, and rheumatoid arthritis $[1,58]$. We have documented that direct contact between MCs and activated T cells or their membranes is associated with Ras activation and sustained ERK phosphorylation, which results in MC activation and mediator release [59,60]. MCs were also found to be activated by EVs derived from activated T cells [14]. These T cell-derived EVs are actively internalized into MCs, a process that can be detected as early as one hour after initiation and appears to be completed after $24 \mathrm{~h}$, resulting in both degranulation and release of specific cytokines such as Oncostatin M, IL-8, and IL-24 [14,61,62].

We also observed that EVs derived from these activated $\mathrm{T}$ cells contained high levels of miR-4443, which was delivered to MCs by the EVs. Mir-4443 serves as a negative regulator of the protein tyrosine phosphatase receptor type J (PTPRJ) gene, known to modulate the Ras signaling pathway by dephosphorylation of ERK [63]. Indeed, delivering miR-4443 into MCs by EVs-derived from activated T cells was found to augment ERK phosphorylation and IL-8 release. Thus, by delivering miR-4443, T cell-derived EVs may 
play an important role in MC activation within T cell-mediated inflammatory processes where MCs are involved [64].

Additionally, perivascular CD301b+ primed DC can shed antigen-bearing EVs after exposure to antigen. These antigen-loaded EVs were capable of trafficking to neighboring MCs and activating them to cause systemic anaphylaxis [65].

A recent study demonstrated that EVs derived from packed red blood cells (EVs-RBC) can activate human MCs, resulting in the increased expression of tryptase and PGD2 and the production of multiple inflammatory mediators, including IL-6, TNF- $\alpha$, IL-4, INF- $\gamma$, CXCL-1, CXCL-5, and LTB-4. The activation of MCs with EVs-RBC also increased the levels of Toll-like receptor-3 (TLR-3) and MAPK activation. Inhibition of the MAPK pathway and TLR-3 resulted in the decreased production of inflammatory mediators, indicating that EVs-RBC activate MCs and elicit the production of multiple inflammatory mediators, partly via the TLR-3 and MAPK pathways. This observation may indicate that EVs-RBC can contribute to potentially harmful outcomes in recipients after blood transfusion by inducing MC activation [66].

Activated MCs participate in the chronic inflammation of cerebral arteries associated with intracranial aneurysm formation and rupture. Activated MCs can infiltrate into the aneurysmal walls and participate in the inflammatory response by releasing a wide range of inflammatory mediators that promote vascular destruction. In various models of organ injury, mesenchymal stem cells (MSC) were found to release EVs, which selectively accumulate at the lesion sites, where they mediate the processes of tissue repair and anti-inflammation by transferring proteins, lipids, and RNA into target cells [67]. Recently, it was demonstrated that MSC-derived EVs can internalize into MCs and prevent the rupture of intracranial aneurysms, in part through suppressing MC activation. The suppressive effect on MCs was mediated via a prostaglandin E2 (PGE2)-dependent mechanism. MSC-EVs increased the synthesis and release of PGE2 and upregulated the expression of the EP4 receptor on MCs, which may be associated with the anti-inflammatory response of MCs [68].

\subsection{Mast Cells as Target of Extracellular Vesicles within the Tumor Microenvironment}

In addition to tumor cells, a variety of other cells, such as stroma cells, fibroblasts, and immune cells, as well as the extracellular matrix and the network of blood-supplying vessels, together form the TME. Several studies have suggested that tumor-derived EVs influence a multitude of processes that aid in tumor progression, including angiogenesis, cellular proliferation, migration, invasion, metastasis, immunoediting, and drug resistance. This can be mediated by transferring bioactive cargos to recipient cells that are found in the TME. These bioactive materials can be comprised of markers and signaling molecules, oncogenic proteins, and nucleic acids, including various RNAs, such as microRNAs [50,69-72] For example, tumor-derived EVs released from the non-small cell lung cancer (NSCLC) cell line A549 were shown to affect endothelial cells and stroma fibroblasts [73]. MCs are often found in the periphery of tumors and have been associated with both pro- and anti-tumorigenic features. The pro- and anti-tumorigenic role of MCs varied according to the tumor type and composition of the TME. Multiple features of the TME may affect the MC phenotype such as the SCF, hypoxia, accumulation of lactic acid, adenosine, PGE2, and low $\mathrm{pH}$ [74-77]. EVs derived from tumor cells are able to activate MCs to release several mediators [78-80]. Thus, EVs derived from NSCLC cells were internalized into MCs, in part by phagocytosis. The interaction of these EVs with MCs resulted in increased ERK phosphorylation, a rapid process that reached a maximal response at $1 \mathrm{~min}$ of activation and declined after $5 \mathrm{~min}$. NSCLC-derived EVs stimulated MCs to release several mediators, such as TNF- $\alpha$ and monocyte chemoattractant protein 1 (MCP-1)/chemokine (C-C motif) ligand 2 (CCL2), as well as enhancing both their chemotactic and chemokinetic activity [78]. The activation of MCs by NSCLC-derived EVs may be due to the transfer of SCF found on EVs to the MCs, which leads to MC activation through SCF-KIT signal transduction [80]. 
In addition, EVs derived from pancreatic and NSCLC lung cancer cells can stimulate MCs to release several other mediators, including IL-8, IL-6, VEGF, and amphiregulin. This activation involves the autocrine formation of adenosine by a CD73-dependent mechanism and activation of the adenosine $\mathrm{A} 3$ receptor, leading to upregulation of tissue remodeling genes [79]. Thus, tumor-derived EVs provide a new possibility, in addition to soluble mediators in the TME, to activate MCs, which, in turn, can affect the cancerous process.

\section{Concluding Remarks}

In addition to being a source of various mediators in response to different stimuli, MCs have recently captured considerable attention as an important source of EVs implicated in many physiological and pathological processes. EVs generated by stimulation differ in terms of size, morphology, and molecular profiles depending on the MC stimulus, in addition to differing from EVs derived from unstimulated MCs. EVs released from MCs can interact with other cell types located in their proximity or at distal sites, including immune cells (T, B, and DC), neurons, and vascular cells (see Figure 1). They act as a vehicle for a wide variety of biological cargo, including lipids, DNA, RNA, and microRNA, to recipient cells. These interactions may influence allergic reactions and inflammation. Furthermore, increasing evidence suggest that MC-derived EVs also have a distinct function in tumor progression. EVs derived from MCs located in the TME can increase the proliferation and migration of tumor cells, as well as induce angiogenesis, stimulate antitumor immune response, and recruit fibroblasts and macrophages [81].

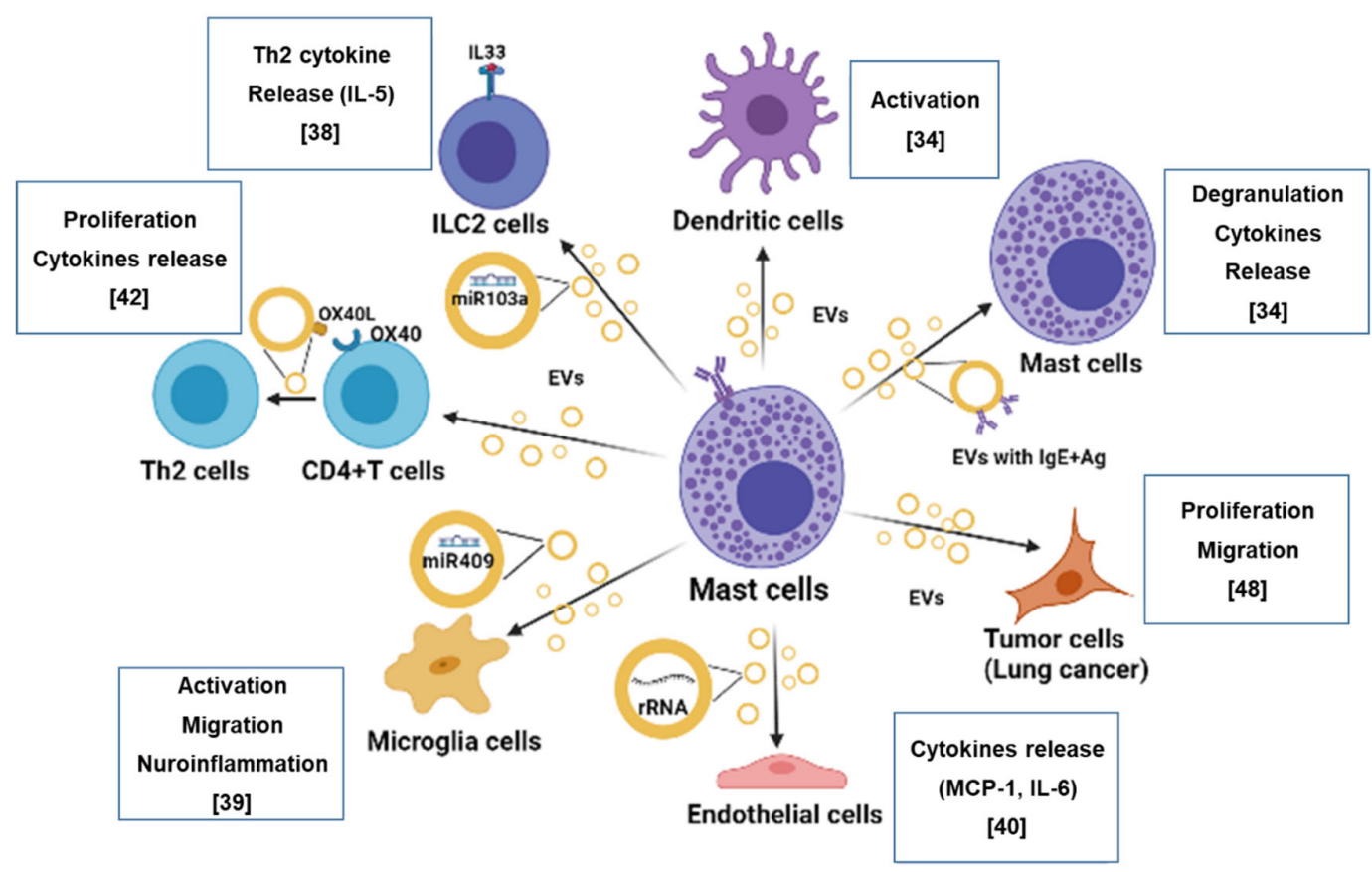

Figure 1. How MC-derived EVs communicate with other cells. The figure illustrates how MCs interact and communicate with other cells via EVs (as indicated in the references). Clockwise: EVs derived from MCs deliver antigens that are presented on their surface, to DC, contributing to allergic responses; EVs derived from FceRI-activated MCs display IgE and antigens on their surface and induce degranulation and cytokine release from MCs; MC-derived EVs enhanced proliferation and migration of lung cancer cells; ribosomal RNA is delivered to endothelial cells by MC-derived EVs and induces the release of pro-inflammatory cytokines; miR-409-3p is carried and transferred by MC-EVs to microglial cells, increasing their migration and release of pro-inflammatory cytokines; MC-derived EVs carry OX40L, which interacts with OX40 present on the surface of T cells, enhancing the differentiation of naïve CD4+ T cells into Th2 cells; EVs derived from MCs deliver miR-103a to IL-33-activted ILC2 and induce IL-5 release. The figure was created with BioRender.com.

Accumulated data also reveal that MCs may serve as a target for EVs that originate from various cell types (see Figure 2). In the context of inflammatory diseases, MCs can be 
activated by EVs derived from activated T cells and DC, thus leading to MC degranulation and cytokine release, in part by delivering miR (such miR-4443) via T cell derived-EVs.

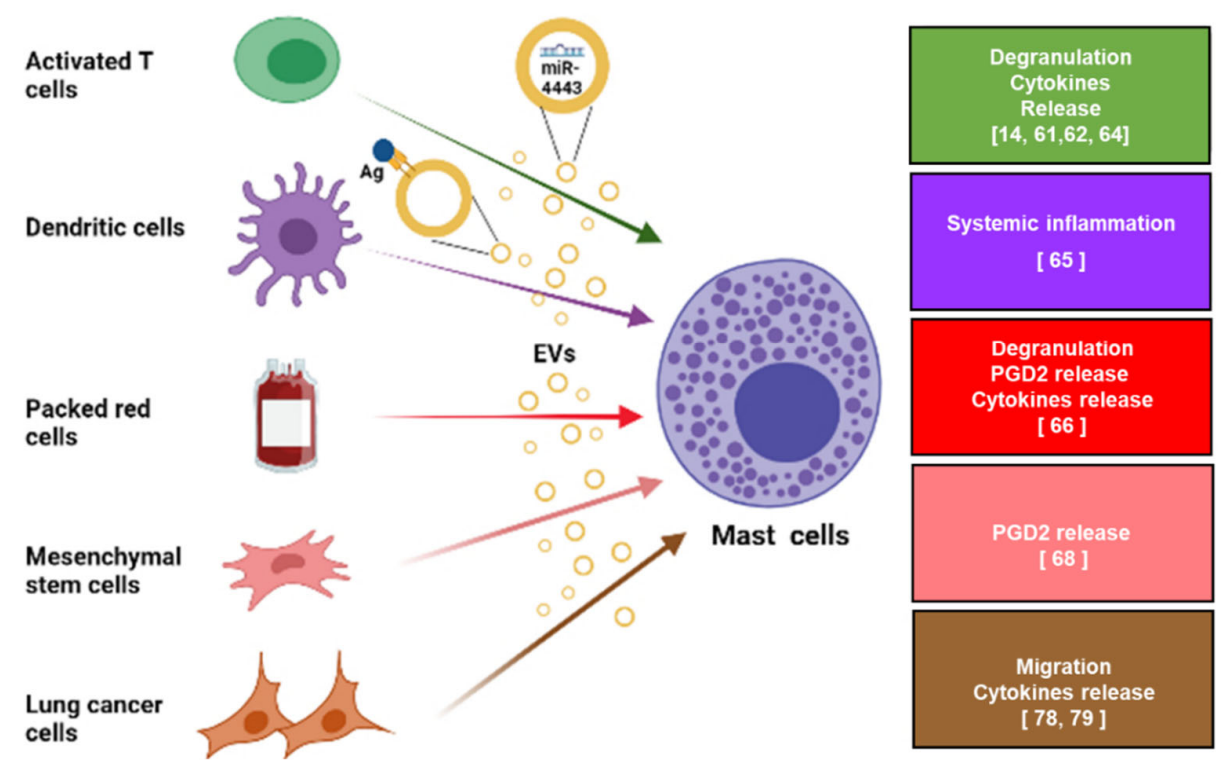

Figure 2. The effect of EVs originating from various cell types on MC activation. MCs may be a target for EVs originating from various cell types. From top to bottom (The colors of the arrows refer to the colors of the boxes): activated T cells release EVs that induce MC degranulation and cytokine release in part by carrying and transferring miR-4443 to MCs; perivascular CD301b+-primed DC can shed antigen-loaded EVs that bind to MCs and activate them; EVs derived from packed red blood cells can activate MCs, resulting in degranulation and release of PGD2 and cytokines; MSC-derived EVs induce the release of PGE2 from MCs; EVs derived from lung cancer cells induce MC migration and cytokine release. The figure was created with BioRender.com.

The presence of MCs in the TME has been well-documented [47]. However, one important question is whether EVs derived from tumor cells can activate MCs. Indeed, our group and others have shown that EVs derived from tumor cells can activate MCs, resulting in enhancing their migration ability and release of specific cytokines.

The possibility that MCs interact with other cell types via EVs may contribute to understanding how MCs communicate with nearby and with distant cells and their contribution to various diseases, as described above. This may help in the development of novel therapeutic modalities. Furthermore, due to the bioactive cargoes of EVs (e.g., miRNAs, nucleic acids, or proteins) and their distribution in most body fluids [82-84], they may provide a promising source of diagnostic biomarkers for MC-related diseases. Indeed, EVs were found to serve as biomarkers in cancer [85], asthma [86], Alzheimer's [87] and kidney disease [88]. However, several limitations, including the lack of sensitive purification method, storage stability, low yield, and purity, limit EV's clinical applications. New EV screening techniques and storage preservation technologies, which are under development, will help to overcome the challenges associated with EV isolation and processing [82,89].

Finally, MCs have been implicated in the pathogenesis of the cytokine storm in COVID-19 [90,91]. It will be interesting to verify whether EVs cause this MC activation.

Author Contributions: I.S. and P.S. wrote the manuscript. I.S. prepared the illustrations. Y.A.M. and P.S. read and critically revised the manuscript. All authors have read and agreed to the published version of the manuscript.

Funding: This research was funded by Israel Cancer Association (\#20190025) to IS and by a research grant from the Israel Science Foundation to Y.A.M.

Acknowledgments: Faye Schreiber edited the manuscript. She is an employee of Meir Medical Center. 
Conflicts of Interest: The authors declare no conflict of interest.

$\begin{array}{ll}\text { Abbreviations } \\ \text { BMMC } & \text { Bone marrow-derived mast cell } \\ \text { CNS } & \text { Central nervous system } \\ \text { DC } & \text { Dendritic cell } \\ \text { EMT } & \text { Epithelial-to-mesenchymal transition } \\ \text { EVs } & \text { Extracellular vesicles } \\ \text { ERK } & \text { Extracellular signal-regulated kinase } \\ \text { HSC } & \text { Hepatic stellate cell } \\ \text { ILC2 } & \text { Group 2 innate lymphoid cell } \\ \text { LTC4 } & \text { Leukotriene C4 } \\ \text { MC } & \text { Mast cell } \\ \text { MSC } & \text { Mesenchymal stem cell } \\ \text { NSCLC } & \text { Non-small cell lung cancer } \\ \text { PGD2 } & \text { Prostaglandin D2 } \\ \text { PGE2 } & \text { Prostaglandin E2 } \\ \text { SCF } & \text { Stem cell factor } \\ \text { SM } & \text { Systemic mastocytosis } \\ \text { TLRs } & \text { Toll-like receptors } \\ \text { TME } & \text { Tumor microenvironment }\end{array}$

\section{References}

1. Mekori, Y.A.; Metcalfe, D.D. Mast cell-T cell interactions. J. Allergy Clin. Immunol. 1999, 104, 517-523. [CrossRef]

2. da Silva, E.Z.; Jamur, M.C.; Oliver, C. Mast cell function: A new vision of an old cell. J. Histochem. Cytochem. 2014, 62, 698-738. [CrossRef] [PubMed]

3. Moon, T.C.; St Laurent, C.D.; Morris, K.E.; Marcet, C.; Yoshimura, T.; Sekar, Y.; Befus, A.D. Advances in mast cell biology: New understanding of heterogeneity and function. Mucosal. Immunol. 2010, 3, 111-128. [CrossRef] [PubMed]

4. Galli, S.J.; Nakae, S.; Tsai, M. Mast cells in the development of adaptive immune responses. Nat. Immunol. 2005, 6, 135-142. [CrossRef] [PubMed]

5. Dyduch, G.; Kaczmarczyk, K.; Okon, K. Mast cells and cancer: Enemies or allies? Pol. J. Pathol. 2012, 63, 1-7. [PubMed]

6. Brockow, K.; Metcalfe, D.D. Mastocytosis. Chem. Immunol. Allergy 2010, 95, 110-124. [CrossRef] [PubMed]

7. Varricchi, G.; Galdiero, M.R.; Loffredo, S.; Marone, G.; Iannone, R.; Marone, G.; Granata, F. Are Mast Cells MASTers in Cancer? Front. Immunol. 2017, 8, 424. [CrossRef]

8. Ribatti, D.; Tamma, R.; Crivellato, E. The dual role of mast cells in tumor fate. Cancer Lett. 2018, 433, 252-258. [CrossRef]

9. el-Lati, S.G.; Dahinden, C.A.; Church, M.K. Complement peptides C3a- and C5a-induced mediator release from dissociated human skin mast cells. J. Investig. Derm. 1994, 102, 803-806. [CrossRef]

10. Ansel, J.C.; Brown, J.R.; Payan, D.G.; Brown, M.A. Substance P selectively activates TNF-alpha gene expression in murine mast cells. J. Immunol. 1993, 150, 4478-4485.

11. Mittal, A.; Sagi, V.; Gupta, M.; Gupta, K. Mast Cell Neural Interactions in Health and Disease. Front. Cell Neurosci. 2019, 13, 110. [CrossRef]

12. Erdei, A.; Andrasfalvy, M.; Peterfy, H.; Toth, G.; Pecht, I. Regulation of mast cell activation by complement-derived peptides. Immunol. Lett. 2004, 92, 39-42. [CrossRef]

13. Marshall, J.S. Mast-cell responses to pathogens. Nat. Rev. Immunol. 2004, 4, 787-799. [CrossRef]

14. Shefler, I.; Salamon, P.; Reshef, T.; Mor, A.; Mekori, Y.A. T cell-induced mast cell activation: A role for microparticles released from activated T cells. J. Immunol. 2010, 185, 4206-4212. [CrossRef] [PubMed]

15. Wernersson, S.; Pejler, G. Mast cell secretory granules: Armed for battle. Nat. Rev. Immunol. 2014, 14, 478-494. [CrossRef] [PubMed]

16. Conti, P.; D’Ovidio, C.; Conti, C.; Gallenga, C.E.; Lauritano, D.; Caraffa, A.; Kritas, S.K.; Ronconi, G. Progression in migraine: Role of mast cells and pro-inflammatory and anti-inflammatory cytokines. Eur. J. Pharmacol. 2019, 844, 87-94. [CrossRef] [PubMed]

17. Groot Kormelink, T.; Arkesteijn, G.J.; van de Lest, C.H. Mast Cell Degranulation Is Accompanied by the Release of a Selective Subset of Extracellular Vesicles That Contain Mast Cell-Specific Proteases. J. Immunol. 2016, 197, 3382-3392. [CrossRef]

18. Cheruvanky, A.; Zhou, H.; Pisitkun, T.; Kopp, J.B.; Knepper, M.A.; Yuen, P.S.; Star, R.A. Rapid isolation of urinary exosomal biomarkers using a nanomembrane ultrafiltration concentrator. Am. J. Physiol. Ren. Physiol. 2007, 292, F1657-F1661. [CrossRef]

19. Théry, C.; Ostrowski, M.; Segura, E. Membrane vesicles as conveyors of immune responses. Nat. Rev. Immunol. 2009, 9, 581-593. [CrossRef] 
20. Lässer, C.; O’Neil, S.E.; Ekerljung, L.; Ekström, K.; Sjöstrand, M.; Lötvall, J. RNA-containing exosomes in human nasal secretions. Am. J. Rhinol. Allergy 2011, 25, 89-93. [CrossRef]

21. Caby, M.P.; Lankar, D.; Vincendeau-Scherrer, C.; Raposo, G.; Bonnerot, C. Exosomal-like vesicles are present in human blood plasma. Int. Immunol. 2005, 17, 879-887. [CrossRef] [PubMed]

22. Zaborowski, M.P.; Balaj, L.; Breakefield, X.O.; Lai, C.P. Extracellular Vesicles: Composition, Biological Relevance, and Methods of Study. Bioscience 2015, 65, 783-797. [CrossRef]

23. Abels, E.R.; Breakefield, X.O. Introduction to Extracellular Vesicles: Biogenesis, RNA Cargo Selection, Content, Release, and Uptake. Cell Mol. Neurobiol. 2016, 36, 301-312. [CrossRef]

24. Kalra, H.; Drummen, G.P.; Mathivanan, S. Focus on Extracellular Vesicles: Introducing the Next Small Big Thing. Int. J. Mol. Sci. 2016, 17, 170. [CrossRef] [PubMed]

25. Dini, L.; Tacconi, S.; Carata, E.; Tata, A.M.; Vergallo, C.; Panzarini, E. Microvesicles and exosomes in metabolic diseases and inflammation. Cytokine Growth Factor Rev. 2020, 51, 27-39. [CrossRef] [PubMed]

26. Ciardiello, C.; Cavallini, L.; Spinelli, C.; Yang, J.; Reis-Sobreiro, M.; de Candia, P.; Minciacchi, V.R.; Di Vizio, D. Focus on Extracellular Vesicles: New Frontiers of Cell-to-Cell Communication in Cancer. Int. J. Mol. Sci. 2016, 17, 175. [CrossRef] [PubMed]

27. Colombo, M.; Raposo, G.; Théry, C. Biogenesis, secretion, and intercellular interactions of exosomes and other extracellular vesicles. Annu. Rev. Cell Dev. Biol. 2014, 30, 255-289. [CrossRef] [PubMed]

28. Aikawa, E.; Alcaraz, M.J.; Anderson, J.D.; Andriantsitohaina, R.; Antoniou, A.; Arab, T.; Archer, F.; Atkin-Smith, G.K.; Ayre, D.C.; Bach, J.M.; et al. Minimal information for studies of extracellular vesicles 2018 (MISEV2018): A position statement of the International Society for Extracellular Vesicles and update of the MISEV2014 guidelines. J. Extracell Vesicles 2018, 23, 1535750. [CrossRef]

29. Shefler, I.; Salamon, P.; Hershko, A.Y.; Mekori, Y.A. Mast cells as sources and targets of membrane vesicles. Curr. Pharm. Des. 2011, 17, 3797-3804. [CrossRef]

30. Vukman, K.V.; Försönits, A.; Oszvald, Á.; Tóth, E.; Buzás, E.I. Mast cell secretome: Soluble and vesicular components. Semin. Cell Dev. Biol. 2017, 67, 65-73. [CrossRef]

31. Lecce, M.; Molfetta, R. FceRI Signaling in the Modulation of Allergic Response: Role of Mast Cell-Derived Exosomes. Int. J. Mol. Sci. 2020, 21, 5464. [CrossRef]

32. Groot Kormelink, T.; Mol, S.; de Jong, E.C.; Wauben, M.H.M. The role of extracellular vesicles when innate meets adaptive. Semin. Immunol. 2018, 40, 439-452. [CrossRef]

33. Liang, Y.; Huang, S.; Qiao, L.; Peng, X.; Li, C.; Lin, K.; Xie, G.; Li, J.; Lin, L.; Yin, Y.; et al. Characterization of protein, long noncoding RNA and microRNA signatures in extracellular vesicles derived from resting and degranulated mast cells. J. Extracell Vesicles 2020, 9, 1697583. [CrossRef]

34. Molfetta, R.; Lecce, M.; Quatrini, L.; Caracciolo, G.; Digiacomo, L.; Masuelli, L.; Milito, N.D.; Vulpis, E.; Zingoni, A.; Galandrini, R.; et al. Immune complexes exposed on mast cell-derived nanovesicles amplify allergic inflammation. Allergy 2020, 75, 1260-1263. [CrossRef]

35. Xie, G.; Yang, H.; Peng, X.; Lin, L.; Wang, J.; Lin, K.; Cui, Z.; Li, J.; Xiao, H.; Liang, Y.; et al. Mast cell exosomes can suppress allergic reactions by binding to IgE. J. Allergy Clin. Immunol. 2018, 141, 788-791. [CrossRef]

36. Ekström, K.; Valadi, H.; Sjöstrand, M.; Malmhäll, C.; Bossios, A.; Eldh, M.; Lötvall, J. Characterization of mRNA and microRNA in human mast cell-derived exosomes and their transfer to other mast cells and blood CD34 progenitor cells. J. Extracell Vesicles 2012, 1. [CrossRef]

37. Valadi, H.; Ekström, K.; Bossios, A.; Sjöstrand, M.; Lee, J.J.; Lötvall, J.O. Exosome-mediated transfer of mRNAs and microRNAs is a novel mechanism of genetic exchange between cells. Nat. Cell Biol. 2007, 9, 654-659. [CrossRef] [PubMed]

38. Toyoshima, S.; Sakamoto Sasaki, T.; Kurosawa, Y.; Hayama, K.; Matsuda, A.; Watanabe, Y.; Terui, T.; Gon, Y.; Matsumoto, K.; Okayama, Y. miR103a-3p in extracellular vesicles from FcERI-aggregated human mast cella enhances IL-5 production by group 2 innate lymphoid cells. J. Allergy Clin. Immunol. 2021, 147, 1878-1891. [CrossRef] [PubMed]

39. Hu, L.; Si, L.; Dai, X.; Dong, H.; Ma, Z.; Sun, Z.; Li, N.; Sha, H.; Chen, Y.; Qian, Y. Exosomal miR-409-3p secreted from activated mast cells promotes microglial migration, activation and neuroinflammation by targeting Nr4a2 to activate the NF- $\mathrm{kB}$ pathway. J. Neuroinflamm. 2021, 18, 68. [CrossRef] [PubMed]

40. Elsemüller, A.K.; Tomalla, V.; Gärtner, U.; Troidl, K.; Jeratsch, S.; Graumann, J.; Baal, N.; Hackstein, H.; Lasch, M.; Deindl, E.; et al. Characterization of mast cell-derived rRNA-containing microvesicles and their inflammatory impact on endothelial cells. Faseb J. 2019, 33, 5457-5467. [CrossRef]

41. Skokos, D.; Le Panse, S.; Villa, I.; Rousselle, J.C.; Peronet, R.; David, B.; Namane, A.; Mécheri, S. Mast cell-dependent B and T lymphocyte activation is mediated by the secretion of immunologically active exosomes. J. Immunol. 2001, 166, 868-876. [CrossRef] [PubMed]

42. Li, F.; Wang, Y.; Lin, L.; Wang, J.; Xiao, H.; Li, J.; Peng, X.; Dai, H.; Li, L. Mast Cell-Derived Exosomes Promote Th2 Cell Differentiation via OX40L-OX40 Ligation. J. Immunol. Res. 2016, 2016, 3623898. [CrossRef] [PubMed]

43. Ackermann, L.; Harvima, I.T.; Pelkonen, J.; Ritamäki-Salo, V.; Naukkarinen, A.; Harvima, R.J.; Horsmanheimo, M. Mast cells in psoriatic skin are strongly positive for interferon-gamma. Br. J. Dermatol. 1999, 140, 624-633. [CrossRef]

44. Cheung, K.L.; Jarrett, R. Psoriatic T cells recognize neolipid antigens generated by mast cell phospholipase delivered by exosomes and presented by CD1a. J. Exp. Med. 2016, 213, 2399-2412. [CrossRef] 
45. Gallo, G.; Vescio, G.; De Paola, G.; Sammarco, G. Therapeutic Targets and Tumor Microenvironment in Colorectal Cancer. J. Clin. Med. 2021, 10, 2295. [CrossRef] [PubMed]

46. Katsuta, E.; Rashid, O.M.; Takabe, K. Clinical relevance of tumor microenvironment: Immune cells, vessels, and mouse models. Hum. Cell 2020, 33, 930-937. [CrossRef]

47. Aponte-López, A.; Muñoz-Cruz, S. Mast Cells in the Tumor Microenvironment. Adv. Exp. Med. Biol. 2020, 1273, 159-173. [CrossRef]

48. Khazaie, K.; Blatner, N.R.; Khan, M.W.; Gounari, F.; Gounaris, E.; Dennis, K.; Bonertz, A.; Tsai, F.N.; Strouch, M.J.; Cheon, E.; et al. The significant role of mast cells in cancer. Cancer Metastasis Rev. 2011, 30, 45-60. [CrossRef] [PubMed]

49. Komi, D.E.A.; Redegeld, F.A. Role of Mast Cells in Shaping the Tumor Microenvironment. Clin. Rev. Allergy Immunol. 2020, 58, 313-325. [CrossRef]

50. Sullivan, R.; Maresh, G.; Zhang, X.; Salomon, C.; Hooper, J.; Margolin, D.; Li, L. The Emerging Roles of Extracellular Vesicles as Communication Vehicles within the Tumor Microenvironment and Beyond. Front. Endocrinol. 2017, 8, 194. [CrossRef]

51. Xiao, H.; Lasser, C.; Shelke, G.V.; Wang, J.; Radinger, M.; Lunavat, T.R.; Malmhall, C.; Lin, L.H.; Li, J.; Li, L.; et al. Mast cell exosomes promote lung adenocarcinoma cell proliferation-role of KIT-stem cell factor signaling. Cell Commun. Signal. 2014, 12, 64. [CrossRef]

52. Yin, Y.; Shelke, G.V.; Lässer, C.; Brismar, H.; Lötvall, J. Extracellular vesicles from mast cells induce mesenchymal transition in airway epithelial cells. Respir. Res. 2020, 21, 101. [CrossRef]

53. Carter, M.C.; Metcalfe, D.D.; Komarow, H.D. Mastocytosis. Immunol. Allergy Clin. N. Am. 2014, 34, 181-196. [CrossRef]

54. Mican, J.M.; Di Bisceglie, A.M.; Fong, T.L.; Travis, W.D.; Kleiner, D.E.; Baker, B.; Metcalfe, D.D. Hepatic involvement in mastocytosis: Clinicopathologic correlations in 41 cases. Hepatology 1995, 22, 1163-1170. [CrossRef] [PubMed]

55. Kim, D.K.; Cho, Y.E.; Komarow, H.D.; Bandara, G.; Song, B.J.; Olivera, A.; Metcalfe, D.D. Mastocytosis-derived extracellular vesicles exhibit a mast cell signature, transfer KIT to stellate cells, and promote their activation. Proc. Natl. Acad. Sci. USA 2018, 115, E10692-E10701. [CrossRef] [PubMed]

56. Orsolini, G.; Viapiana, O.; Rossini, M.; Bonifacio, M.; Zanotti, R. Bone Disease in Mastocytosis. Immunol. Allergy Clin. N. Am. 2018, 38, 443-454. [CrossRef]

57. Kim, D.K.; Bandara, G.; Cho, Y.E.; Komarow, H.D.; Donahue, D.R. Mastocytosis-derived extracellular vesicles deliver miR-23a and miR-30a into pre-osteoblasts and prevent osteoblastogenesis and bone formation. Nat. Commun 2021, 12, 2527. [CrossRef]

58. Mekori, Y.A. The mastocyte: The "other" inflammatory cell in immunopathogenesis. J. Allergy Clin. Immunol. 2004, 114, 52-57. [CrossRef] [PubMed]

59. Shefler, I.; Mekori, Y.A.; Mor, A. Stimulation of human mast cells by activated T cells leads to N-Ras activation through Ras guanine nucleotide releasing protein 1. J. Allergy Clin. Immunol. 2008, 122, 1222-1225. [CrossRef]

60. Mor, A.; Shefler, I.; Salamon, P.; Kloog, Y.; Mekori, Y.A. Characterization of ERK activation in human mast cells stimulated by contact with T cells. Inflammation 2010, 33, 119-125. [CrossRef]

61. Salamon, P.; Shoham, N.G.; Puxeddu, I.; Paitan, Y.; Levi-Schaffer, F.; Mekori, Y.A. Human mast cells release oncostatin M on contact with activated T cells: Possible biologic relevance. J. Allergy Clin. Immunol. 2008, 121, 448-455.e5. [CrossRef]

62. Shefler, I.; Pasmanik-Chor, M.; Kidron, D.; Mekori, Y.A.; Hershko, A.Y. T cell-derived microvesicles induce mast cell production of IL-24: Relevance to inflammatory skin diseases. J. Allergy Clin. Immunol. 2014, 133, 217-224.e3. [CrossRef]

63. Sacco, F.; Tinti, M.; Palma, A.; Ferrari, E.; Nardozza, A.P.; van Huijsduijnen, R.H.; Takahashi, T.; Castagnoli, L.; Cesareni, G. Tumor suppressor density-enhanced phosphatase-1 (DEP-1) inhibits the RAS pathway by direct dephosphorylation of ERK1/2 kinases. J. Biol. Chem. 2009, 284, 22048-22058. [CrossRef] [PubMed]

64. Shefler, I.; Salamon, P.; Levi-Schaffer, F.; Mor, A.; Hershko, A.Y.; Mekori, Y.A. MicroRNA-4443 regulates mast cell activation by T cell-derived microvesicles. J. Allergy Clin. Immunol. 2018, 141, 2132-2141.e4. [CrossRef] [PubMed]

65. Choi, H.W.; Suwanpradid, J.; Kim, I.H.; Staats, H.F. Perivascular dendritic cells elicit anaphylaxis by relaying allergens to mast cells via microvesicles. Science 2018, 362. [CrossRef] [PubMed]

66. Fang, X.; Li, J.; Hao, X.; Zhang, W.; Zhong, J.; Zhu, T.; Liao, R. Exosomes From Packed Red Cells Induce Human Mast Cell Activation and the Production of Multiple Inflammatory Mediators. Front. Immunol. 2021, 12, 677905. [CrossRef]

67. Bruno, S.; Grange, C.; Deregibus, M.C.; Calogero, R.A.; Saviozzi, S.; Collino, F.; Morando, L.; Busca, A.; Falda, M.; Bussolati, B.; et al. Mesenchymal stem cell-derived microvesicles protect against acute tubular injury. J. Am. Soc. Nephrol. 2009, 20, $1053-1067$. [CrossRef]

68. Liu, J.; Kuwabara, A.; Kamio, Y.; Hu, S.; Park, J.; Hashimoto, T.; Lee, J.W. Human Mesenchymal Stem Cell-Derived Microvesicles Prevent the Rupture of Intracranial Aneurysm in Part by Suppression of Mast Cell Activation via a PGE2-Dependent Mechanism. Stem Cells 2016, 34, 2943-2955. [CrossRef]

69. Bian, X.; Xiao, Y.T.; Wu, T.; Yao, M.; Du, L.; Ren, S.; Wang, J. Microvesicles and chemokines in tumor microenvironment: Mediators of intercellular communications in tumor progression. Mol. Cancer 2019, 18, 50. [CrossRef]

70. Kogure, A.; Kosaka, N.; Ochiya, T. Cross-talk between cancer cells and their neighbors via miRNA in extracellular vesicles: An emerging player in cancer metastasis. J. Biomed. Sci. 2019, 26, 7. [CrossRef]

71. Maacha, S.; Bhat, A.A.; Jimenez, L.; Raza, A.; Haris, M.; Uddin, S.; Grivel, J.C. Extracellular vesicles-mediated intercellular communication: Roles in the tumor microenvironment and anti-cancer drug resistance. Mol. Cancer 2019, 18, 55. [CrossRef]

72. O'Driscoll, L. Expanding on exosomes and ectosomes in cancer. N. Engl. J. Med. 2015, 372, 2359-2362. [CrossRef] 
73. Wysoczynski, M.; Ratajczak, M.Z. Lung cancer secreted microvesicles: Underappreciated modulators of microenvironment in expanding tumors. Int. J. Cancer 2009, 125, 1595-1603. [CrossRef]

74. Huang, B.; Lei, Z.; Zhang, G.M.; Li, D.; Song, C.; Li, B.; Liu, Y.; Yuan, Y.; Unkeless, J.; Xiong, H.; et al. SCF-mediated mast cell infiltration and activation exacerbate the inflammation and immunosuppression in tumor microenvironment. Blood 2008, 112, 1269-1279. [CrossRef] [PubMed]

75. Gulliksson, M.; Carvalho, R.F.; Ullerås, E.; Nilsson, G. Mast cell survival and mediator secretion in response to hypoxia. PLoS ONE 2010, 5, e12360. [CrossRef] [PubMed]

76. Gottfried, E.; Kreutz, M.; Mackensen, A. Tumor metabolism as modulator of immune response and tumor progression. Semin. Cancer Biol. 2012, 22, 335-341. [CrossRef] [PubMed]

77. Gorzalczany, Y.; Sagi-Eisenberg, R. Role of Mast Cell-Derived Adenosine in Cancer. Int. J. Mol. Sci. 2019, 20, 2603. [CrossRef]

78. Salamon, P.; Mekori, Y.A.; Shefler, I. Lung cancer-derived extracellular vesicles: A possible mediator of mast cell activation in the tumor microenvironment. Cancer Immunol. Immunother. 2020, 69, 373-381. [CrossRef]

79. Gorzalczany, Y.; Merimsky, O.; Sagi-Eisenberg, R. Mast Cells Are Directly Activated by Cancer Cell-Derived Extracellular Vesicles by a CD73- and Adenosine-Dependent Mechanism. Transl. Oncol. 2019, 12, 1549-1556. [CrossRef]

80. Xiao, H.; He, M.; Xie, G.; Liu, Y.; Zhao, Y.; Ye, X.; Li, X.; Zhang, M. The release of tryptase from mast cells promote tumor cell metastasis via exosomes. BMC Cancer 2019, 19, 1015. [CrossRef]

81. Benito-Martin, A.; Di Giannatale, A.; Ceder, S.; Peinado, H. The new deal: A potential role for secreted vesicles in innate immunity and tumor progression. Front. Immunol. 2015, 6, 66. [CrossRef]

82. Zhou, X.; Xie, F.; Wang, L.; Zhang, L.; Zhang, S.; Fang, M.; Zhou, F. The function and clinical application of extracellular vesicles in innate immune regulation. Cell Mol. Immunol. 2020, 17, 323-334. [CrossRef]

83. Ludwig, N.; Whiteside, T.L.; Reichert, T.E. Challenges in Exosome Isolation and Analysis in Health and Disease. Int. J. Mol. Sci. 2019, 20, 4684. [CrossRef]

84. De Toro, J.; Herschlik, L.; Waldner, C.; Mongini, C. Emerging roles of exosomes in normal and pathological conditions: New insights for diagnosis and therapeutic applications. Front. Immunol. 2015, 6, 203. [CrossRef] [PubMed]

85. Urabe, F.; Kosaka, N.; Ito, K.; Kimura, T.; Egawa, S.; Ochiya, T. Extracellular vesicles as biomarkers and therapeutic targets for cancer. Am. J. Physiol. Cell Physiol. 2020, 318, C29-C39. [CrossRef] [PubMed]

86. Nazimek, K.; Bryniarski, K.; Askenase, P.W. Functions of Exosomes and Microbial Extracellular Vesicles in Allergy and Contact and Delayed-Type Hypersensitivity. Int. Arch. Allergy Immunol. 2016, 171, 1-26. [CrossRef] [PubMed]

87. Badhwar, A.; Haqqani, A.S. Biomarker potential of brain-secreted extracellular vesicles in blood in Alzheimer's disease. Alzheimers Dement. (Amst.) 2020, 12, e12001. [CrossRef] [PubMed]

88. Zhang, W.; Zhou, X.; Zhang, H.; Yao, Q.; Liu, Y.; Dong, Z. Extracellular vesicles in diagnosis and therapy of kidney diseases. Am. J. Physiol. Ren. Physiol. 2016, 311, F844-F851. [CrossRef] [PubMed]

89. Barile, L.; Vassalli, G. Exosomes: Therapy delivery tools and biomarkers of diseases. Pharmacol. Ther. 2017, 174, 63-78. [CrossRef]

90. Conti, P.; Ronconi, G.; Caraffa, A.; Gallenga, C.E.; Ross, R.; Frydas, I.; Kritas, S.K. Induction of pro-inflammatory cytokines (IL-1 and IL-6) and lung inflammation by Coronavirus-19 (COVI-19 or SARS-CoV-2): Anti-inflammatory strategies. J. Biol. Regul. Homeost. Agents 2020, 34, 327-331. [CrossRef]

91. Theoharides, T.C.; Conti, P. COVID-19 and Multisystem Inflammatory Syndrome, or is it Mast Cell Activation Syndrome? J. Biol. Regul. Homeost. Agents 2020, 34, 1633-1636. [CrossRef] [PubMed] 